\title{
Práticas de reescrita: possibilidades de instauração da autoria
}

Filomena Elaine Assolin*

Camila Carrari Dornelas**

\section{Resumo}

Apresentamos resultados de pesquisa concluída que investigou as práticas de reescrita como possibilidade de instauração da autoria em textos acadêmicos produzidos por estudantes universitários. Trazemos, ainda, resultados concernentes à relação que esses estudantes estabelecem com a escrita e as possibilidades de ressignificação desse objeto simbólico, a partir da reescrita. O arcabouço teórico que sustenta essa investigação é constituído pela análise de discurso pêcheuxtiana, pela psicanálise freudo-lacaniana, pelas contribuições das ciências da educação, em particular as que se referem aos estudos sobre a formação de professores. Dentre as conclusões às quais chegamos, salientamos aquelas que assinalam que a (re)escrita constitui alternativa para o sujeito "falar de si", subjetivar-se e aprender a lidar com a alteridade que lhe constitui. Outra conclusão diz respeito ao entendimento segundo o qual a reescrita, quando realizada em condições adequadas de produção, possibilita a emergência da autoria.

Palavras-chave: Reescrita. Subjetividade. Alteridade. Autoria. Universidade.

\section{Contextualizando a pesquisa e seus fundamentos teórico-metodológicos}

Como docente de cursos de graduação, preocupa-nos, há certo tempo, a formação inicial de estudantes, particularmente os de pedagogia, licenciandos que irão atuar no ensino fundamental, quer seja no âmbito da sala de aula quer na gestão escolar. Em ambos os casos, precisarão da escrita, cotidianamente, para as mais diversas tarefas e atividades relacionadas ao ofício. A pesquisa

\footnotetext{
Docente dos cursos de graduação e pós-graduação em Educação da Faculdade de Filosofia, Ciências e Letras de Ribeirão Preto da Universidade de São Paulo. Coordenadora do Grupo de Estudos e Pesquisas sobre Alfabetização, Leitura e Letramento. E-mail: elainefdoc@ ffclrp.usp.br

** Mestranda no Programa de Pós-Graduação em Educação pela Faculdade de Filosofia, Ciências e Letras de Ribeirão Preto da Universidade de São Paulo. Pesquisadora do Grupo de Estudos e Pesquisas sobre Alfabetização, Leitura e Letramento. E-mail: carrari@usp.br
}
Data de submissão: mar. 2016 - Data de aceite: maio 2016 http://dx.doi.org/10.5335/rdes.v12i1.5818


por nós realizada, recentemente concluída, financiada, intitulada A relação de estudantes universitários com a escrita: consequências para a constituição de suas identidades profissionais (Fapesp, Pró-Reitoria de Graduação), trouxe indícios de que, para parte considerável dos estudantes, cujos dizeres foram analisados, produzir textos acadêmicos é tarefa árdua, desgastante e desagradável, sendo que, em alguns casos, há desistências da produção escrita, propriamente dita, já no início do texto. Alguns relacionam-se negativamente com essa prática cultural, o que indicia uma memória discursiva, cujos sentidos, em relação à escrita, evocam percepções de que escrever academicamente é possível somente para aqueles a quem foram conferidos "dons", "talentos", "habilidades" e "competências" diferenciadas.

As análises e reflexões, decorrentes dessa pesquisa, instigaram-nos à realização de outra investigação - A instauração da autoria por meio de práticas de reescrita: possibilidades, limites e perspectivas. Partindo do pressuposto de que a reescrita possibilita ao sujeito ocupar o "lugar de autor" (TFOUNI, 2005), buscamos compreender se e em que condições de produção a prática da reescrita de textos acadêmicos possibilita a emergência da autoria, condição basilar para o exercício responsável da docência.

Para alcançar nosso objetivo, valemo-nos de um arcabouço teórico-metodológico, tramado por meio de fios da análise de discurso de matriz francesa, da psicanálise freudo-lacaniana e de algumas contribuições das ciências da educação, em especial as que dizem respeito à formação de professores. A análise de discurso de matriz francesa (pêcheuxtiana), campo teórico ao qual nos filiamos desde sempre, traz os conceitos de memória discursiva, formação discursiva, formação ideológica, texto, dentre outras noções. A análise de discurso pêcheuxtiana (doravante $\mathrm{AD}$ ) trabalha não com produtos, mas com os processos e as condições de produção da linguagem.

Buscando instaurar os fundamentos da $\mathrm{AD}$ e trabalhando a relação língua-discurso-ideologia, Pêcheux e Fuchs ([1975] 1990) afirmam que o discurso é a materialidade específica da ideologia, e a materialidade específica do discurso é a língua. $\mathrm{O}$ discurso, dessa forma, é o lugar em que se observa a relação entre língua e ideologia, e a língua é que produz sentidos por e para os sujeitos. Produzido em um espaço de redes de filiações socio-históricas de sentido, “[...] o discurso marca a possibilidade de uma desestruturação-reestruturação dessas redes e trajetos" (PÊCHEUX, 1999, p. 56).

A psicanálise freudo-lacaniana promove o deslocamento da noção de indivíduo, capaz de controlar os sentidos de seu dizer, para a de sujeito, que se constitui na relação com o simbólico, com a história, sendo sua autonomia uma ilusão. A essa importante contribuição 
somam-se as noções de alteridade e subjetividade, essenciais neste trabalho.

Aárea concernente à formação de professores nos dá sustentação teórica para compreendermos a formação inicial como um processo múltiplo, não linear, cujas vozes, memória discursiva, saberes, práticas e experiências, acumulados ao longo da história do sujeito e, portanto, de seu percurso histórico-social e ideológico, afetam sobremaneira o modo como se relaciona com os objetos do conhecimento, de maneira ampla, e com a escrita, de forma particular, além de influenciarem a constituição da identidade profissional do sujeito estudante, que, futuramente, poderá atuar nos dois primeiros ciclos da educação básica, nos ensinos infantil e fundamental, assim como na coordenação e gestão educacional.

Neste artigo, apresentaremos pequeno recorte da citada pesquisa - A instauração da autoria por meio de práticas de reescrita: possibilidades, limites e perspectivas -, concluída no final do ano 2015. Em um primeiro momento, trazemos alguns importantes conceitos das bases teóricas que sustentaram nosso estudo e, em seguida, a constituição do corpus. Na terceira seção, expomos as análises discursivas, nascidas de nossos gestos interpretativos e, por fim, algumas das conclusões a que chegamos, a partir das interpretações realizadas, tendo em vista os indícios linguístico-discursivos aos quais nos ativemos.

\section{A relação entre subjetividade e alteridade na constituição do sujeito: contribuições da análise de discurso pêcheuxtiana e da psicanálise}

Destacamos, inicialmente, que partimos da noção de um sujeito interpelado ideologicamente, cindido, porque assume várias posições no discurso, e clivado, por ser fragmentado, uma vez que o inconsciente o constitui. Atravessado pelo inconsciente, constituído na relação com o outro, na interlocução com o meio socio-histórico, o sujeito não tem acesso ao modo como os sentidos se constituem nele, uma vez que é afetado pela memória discursiva e pelas suas filiações de sentido.

O discurso, que mantém sempre relação com outros dizeres, não é uma entidade homogênea, visto que é caracterizado pela alteridade e multiplicidade de discursos já-ditos, realizados ou possíveis, pois "[...] sempre sob as palavras, outras palavras são ditas" (AUTHIER-REVUZ, 1990, p. 28). Assim, todo discurso faz circular discursos anteriores, já formulados, promovendo o ressoar de sentidos.

Assinalar que o discurso é marcado pela alteridade implica salientar uma importante contribuição lacaniana: não há sujeito sem outro. O psicanalista francês, Jacques Marie Émile Lacan (1901-1981), na década de 1960, retor- 
na à obra freudiana e problematiza a dupla dimensão da alteridade, distinguindo e grafando o pequeno outro (com o minúsculo) do grande Outro (com $\mathrm{O}$ maiúsculo). No primeiro caso, a ênfase é colocada no lugar e na função de nosso semelhante da espécie humana, nossos iguais. No segundo, o Outro configura-se enquanto campo simbólico da linguagem, formado por todos os outros que, na infância, ocuparam lugares importantes, como mãe, pai, avó, avô, tio, tia, professores. Enigmático e detentor das chaves de significações inacessíveis ao sujeito, esse grande Outro é o lugar do inconsciente, o "tesouro dos significantes" (LACAN, [1966] 1998). Constituído por palavras marcantes daqueles com os quais nos relacionamos na infância, $o$ inconsciente determina escolhas, sintomas e os desejos do sujeito. Importa salientar, também, que o inconsciente como discurso do Outro nos indica que:

[...] não só ele é estruturado como uma linguagem mas que o lugar do Outro equivale ao lugar do código pessoal dos significantes do sujeito. O grande Outro é o conjunto de significantes que marcam o sujeito em sua história, seu desejo, seus ideais-eles sustentam suas fantasias inconscientes e imaginárias (QUINET, 2012, p. 24).

É imprescindível dizer que a descoberta do inconsciente por Sigmund Freud (1856-1939) revoluciona a noção de sujeito, pois o médico e psicanalista comprova que a consciência é a parte mínima da vida psíquica. A compreensão de sujeito, segundo a qual esse seria uma entidade homogênea e ciente do que diz, é refutada a partir da concepção freudiana de sujeito clivado, dividido entre consciente e inconsciente. Coube também a Freud ([1925] 2011) trazer a ideia de alteridade na interioridade. $\mathrm{O}$ ego ou o eu (para os lacanianos) é, assim, formado pelo conjunto de identificações por nós vivenciadas ao longo de nossa existência.

Desenvolvendo essa reflexão, é pertinente afirmar que o inconsciente, mais do que o lugar da subjetividade, é o discurso do Outro, é o desejo do Outro. É a esse Outro, que antecede a própria existência do indivíduo, a quem ele tem de se assujeitar para se constituir como sujeito. Nesse embate com o Outro da linguagem, o sujeito se perde e se aliena. O sujeito entra no simbólico por uma simbolização da imagem do corpo próprio e, por isso mesmo, fica definitivamente marcado pela linguagem.

A imagem de um mosaico pode representar esse conjunto de identificações que nos constitui, a alteridade, da qual não podemos escapar nem nos desfazer. Portanto, somos muitos, saibamos ou não, queiramos ou não.

Salientamos que a subjetividade contemporânea é marcada pela fragmentação. Se a subjetividade construída no início da modernidade era constituída por noções de interioridade e reflexão sobre si mesma, na atualidade, ela é marcada pelo autocentramento, assumindo uma configuração em que o olhar do outro no campo social passa a ocupar uma posição estratégica de economia psíquica no sujeito (BIRMAN, 2003). 


\section{Escrita e reescrita: algumas noções fundamentais}

Apresentaremos, nesta seção, algumas noções de escrita e reescrita e as bases fundamentais de nosso pressuposto maior, qual seja, o de que a prática da reescrita possibilita ao estudante, licenciando em pedagogia, ocupar a posição de autor de seu próprio dizer. Dialogaremos com os teóricos por nós selecionados, considerando nossa concordância com seus postulados e formulações, que nos dão embasamento para as interpretações, análises discursivas e reflexões a serem realizadas.

Iniciemos, então, com o filósofo Michel Foucault (1992), destacando o seu importante texto $A$ escrita de si, que pode ser compreendida como uma forma (processual) de o sujeito voltar-se para si mesmo. Esse gesto, o de reportar-se a si mesmo, pode se dar tanto por meio da escrita quanto da fala, visto que ambas promovem a emergência dos processos de subjetivação e do identificatório. Destaquemos que: “[...] escrever é mostrar-se, dar-se a ver, fazer aparecer o rosto próprio junto ao outro" (FOUCAULT, 2004, p. 156).

Ressaltemos que a escrita produz, simultaneamente, dois movimentos: um para dentro, in-scripta, e outro para fora, ex-scripta. A escrita traz a inscrição daquele que expõe seus pensamentos, argumentos e afetos, implicando na inscrição daquele que escreve, ao mesmo tempo em que o sujeito é envolvido, marcado e afetado pelo que escreve.

A seção intitulada "A correspondência" (FOUCAULT, 2004), interessa-nos sobremaneira, pois o estudioso discorre sobre "os cadernos de notas", exercícios de escrita pessoal, que são regidos pelos princípios da "verdade local da máxima" e "valor circunstancial de uso". O filósofo traz, ainda, sua reflexão sobre a escrita de cartas que, segundo ele, afetam tanto aquele que as envia quanto aquele que as recebe, pois, em ambos os casos, há possibilidades de releitura e de reescrita do escrito, do falado ou de ambos. Assim:

[...] a correspondência não deve ser encarada como simples prolongamento da prática dos hypommenata. É algo mais do que um adestramento de si pela escrita, por intermédio dos conselhos e opiniões que se dão ao outro: ela constitui uma certa maneira de cada um se manifestar a si próprio e aos outros (FOUCAULT, 2004, p. 158).

No âmbito dessa discussão, apresentamos a noção de escrita com a qual concordamos:

[...] a escrita articula-se entre o linguístico, o histórico, o social, o ideológico, constituindo-se num espaço simbólico, lugar de interpretação, memória e construção de identidades (GRIGOLETTO, 2006, p. 145).

Agustini e Grigoletto (2008) acrescentam mais um elemento na articulação da prática da escrita: o inconsciente. Em concordância com as pesquisadoras, ressaltamos que a escrita pode, em muitos casos, revelar o inconsciente do sujeito; inconsciente aqui entendido à luz de Lacan (1998), ou seja: "estruturado como linguagem", sendo essa a condição do inconsciente. Dessa forma, 
[...] se a psicanálise encontra sua viabilidade, se finalmente o inconsciente torna-se abordável, apesar de sua vocação à incomunicabilidade, é graças a esse caráter visual da letra e da escrita, bem como a tendência de ambas a passarem despercebidas (MACHADO, 2000, p. 154).

É interessante observar que o psicanalista francês Lacan destaca a inacessibilidade ao real, mas, ao mesmo tempo, atribui à letra o poder de conseguir capturar o impossível. Assim, “[...] o Real é apenas possível de ser escrito, é o que não cessa de se escrever. O Real é o possível à espera de ser escrito" (LACAN, 1988, p. 24).

O real ainda não é, mas ele pode vir a ser escrito. Nessa linha de raciocínio, podemos pensar que a escrita representa uma espécie de saída do real, que passaria a se integrar no circuito simbólico. Se, historicamente, é graças à escrita que o homem é lembrado como um ser de cultura, que se torna imortal a partir do registro escrito de seus feitos, como narra o mito de Gilgamesh, ${ }^{1}$ não é difícil concordar com o postulado lacaniano, segundo o qual a única via possível para atingir o real é lançando mão da escrita.

Para adensar nossa discussão, evocamos o Seminário Livro 18, De um discurso que não seria semblante, no qual Lacan ([1971] 2009) declara sua surpresa diante da afinidade dos gregos com as letras. Entusiasmado com o trabalho do reconhecido historiador da escrita Fèvrier, a respeito dos caminhos da escrita ao longo da história da humanidade, Lacan atém-se ao equívoco entre "as normas" e "o enorme da escrita", les normes e l'enorme, que, em francês, são perfeitamente homofônicos. Cumpre dizer que o próprio Fèvrier não havia se dado conta da homofonia, com a qual Lacan ([1971] 2009) brinca e joga. Essa brincadeira, esse jogo traz "o enorme da escrita" como um sintoma a ser decifrado. A arguta percepção lacaniana, "o enorme da escrita", sensibiliza-nos e instiga-nos a decifrar e compreender esse objeto simbólico, a escrita.

Retomando nossa hipótese, segundo a qual a reescrita se oferece como oportunidade para a instauração do processo de construção da autoria, destacamos que encontramos nos postulados de Tfouni $(1995,2001)$ inspiração e sustentação teórica para o nosso argumento, pois, para ocupar a posição de autor, segundo a estudiosa, se faz necessário que o sujeito retroaja sobre o processo de produção de sentidos e ocupe o que denomina "lugar de autor" (TFOUNI, 2001). Esse "lugar" permite ao sujeito olhar para o texto a partir de diferentes perspectivas e mobilizar recursos linguístico-discursivos e inconscientes, que lhe permitem fazer movimentos de retorno ao enunciado e amarrar a inevitável dispersão de sentidos, que está sempre se instalando, graças à falha, ao equívoco e à polissemia, constitutivos da língua.

A prática da reescrita, concebida aqui como "[...] conjunto de modificações escriturais pelas quais diversos estados do texto constituem as sequências recuperáveis visando um texto terminal" 
(FIAD, 2009, p. 148), é por nós tratada como sendo alternativa viável para o sujeito do discurso ocupar o lugar de autor, visto que esse pode retroceder, retomar o seu dizer e suas interpretações, o que pode lhe ajudar a aprender a escutar os sentidos que (re)produz.

Cumpre notar que trabalhamos com a ideia de que ao reescrever um texto o sujeito tem dele uma compreensão que é da ordem do não repetível, pois, mesmo que o sujeito mantenha os sentidos sedimentados no texto primeiro (texto-origem), teremos outras condições de produção para a produção textual, o sujeito, por sua vez, poderá ocupar outros lugares, falando a partir de outras posições e, assim, outras vozes, dizeres e sentidos provenientes de sua memória discursiva irão se fazer presentes na sua reescrita.

Temos como pressuposto que, para (re)escrever algo, é necessário que o sentido já constitua o sujeito. Assim, é correto afirmar que (re)escritas são decorrentes, também, de um trabalho da memória discursiva, pois para que nossas palavras tenham sentido é preciso que elas já façam sentido. Palavras já ditas e esquecidas, ao longo do tempo e de nossas experiências, continuam nos afetando, posto que são atualizadas. Temos, assim, o efeito do interdiscurso, ou seja, de "[...] todo o conjunto de formulações feitas e esquecidas que determinam o que dizemos" (ORLANDI, 1999, p. 53). Cumpre lembrar que o interdiscurso, em sua intrincação com o complexo de formações ideológicas que "[...] fornece a cada sujeito sua 'realidade', enquanto sistemas de evidências e de significações percebidas-aceitas-experimentadas" (PÊCHEUX, 1995, p. 162, grifo do autor), é da ordem do saber discursivo, memória afetada pelo esquecimento.

Prosseguindo com a nossa argumentação, lembramos que uma "escuta sensível" e aguçada dos sentidos que (re) produz é condição basilar para a docência responsável, pois pode permitir ao estudante e futuro professor inscrever-se em zonas de sentido que valorizem e acionem o seu interdiscurso, (re)mexendo com os seus saberes, escolares ou não. Escutar para além do que está institucionalmente legitimado, acolher a opacidade da linguagem, a relação entre o simbólico e as relações de poder e trabalhar os lugares em que os sentidos sejam outros bem como inserir-se em novas formações discursivas, que lhes deem oportunidades para inaugurar e constituir sua própria memória discursiva pessoal, são algumas das contribuições advindas do que denominamos "escuta sensível".

Tendo apresentado algumas noções de escrita e de reescrita, passaremos a discorrer sobre os aspectos metodológicos de nossa investigação.

\section{Aspectos metodológicos: constituição do corpus e procedimento de análise}

Na perspectiva teórica da $\mathrm{AD}$, considera-se a materialidade linguística no ponto em que se unem linguística, 
ideologia e inconsciente. De acordo com esse campo teórico, a língua é entendida como materialidade linguística e, em razão de sua porosidade e possibilidade de equívoco, pode ser desconstruída pela análise do funcionamento discursivo, oferecendo-nos diferentes possibilidades de interpretação.

Assim, só podemos falar em corpus a partir de um recorte de dados, determinado pelas condições de produção, levando-se em conta os objetivos e princípios teóricos que, orientando toda a análise, possibilitam uma leitura não subjetiva dos dados, entendidos aqui como fatos linguísticos, posto que, diferentemente dos dados, têm historicidade e memória, elementos que se inscrevem na língua e no discurso.

Com base nesse entendimento, constituímos o corpus a partir de entrevistas realizadas com quarenta estudantes do curso de licenciatura em Pedagogia, de uma universidade pública do interior paulista, ao longo da realização de um curso de extensão universitária, cujo período foi de março a setembro de 2015. Coletamos depoimentos escritos desses sujeitos a respeito de suas relações com a escrita acadêmica. Esses depoimentos foram produzidos durante as atividades de leitura e escrita realizadas ao longo dos dez encontros que constituíram o curso de extensão Práticas de Reescrita.

Compõem, também, o corpus cerca de 260 textos de reescritas, ou seja, produções textuais realizadas a partir de textos acadêmicos, escolhidos por nós e pelos próprios estudantes participantes do nosso projeto. Esses textos, de diferentes autores, versam sobre distintos temas relacionados às disciplinas, como formação profissional, avaliação, prática pedagógica, leitura e escrita, a partir da perspectiva discursiva, estratégias de ensinagem, etc. As concepções desses quarenta estudantes a respeito de escrita acadêmica e leitura integram também o nosso corpus.

Para este artigo, especificamente, foram selecionados quatro recortes, sendo que o primeiro traz a produção linguística escrita referente à seção Conclusão de um relatório final de estágio, elaborado por um dos quarenta estudantes universitários com os quais trabalhamos no curso de extensão universitária Práticas de Reescrita. $\mathrm{O}$ segundo recorte traz a reescrita dessa seção, Conclusão, elaborada pelo mesmo sujeito estudante universitário, identificado pela sigla SE14, nomenclatura utilizada para a não identificação do sujeito.

Os outros dois recortes, denominados $\mathrm{A}$ e $\mathrm{B}$, trazem depoimentos de um único estudante, a respeito de sua relação com a leitura (recorte A) e, também, sobre sua experiência com a prática da reescrita (recorte B). O sujeito estudante foi identificado como SE37, a fim de que pudéssemos manter em sigilo sua identidade.

Tendo organizado os recortes discursivos, concebidos como "[...] fragmentos correlacionados de linguagem e situação" (ORLANDI, 1987, p. 139), e consideran- 
do os objetivos desta pesquisa, selecionamos para análise algumas sequências discursivas de referência (SDRs), concebidas por Courtine como "[...] sequências orais ou escritas, de dimensão superior à frase" (1981, p. 25).

Detivemo-nos nesses recortes e, em especial, nas sequências discursivas de referência, buscando indícios linguístico-discursivos que atestassem a relação entre o sujeito e a linguagem no texto. Esses indícios levam-nos ao processo discursivo, possibilitando-nos explicar o funcionamento do discurso e a relação entre esse funcionamento e as formações discursivas que, por sua vez, remetem às formações ideológicas. Estamos, pois, fundamentados no paradigma indiciário, tal como proposto por Ginzburg (1989), que nos ensina a perscrutar, perseguir e esmiuçar indícios, marcas e sinais que nos chamaram a atenção e nos causaram estranhamento.

É pertinente, nesse contexto, explicitar os conceitos de formação discursiva e formação ideológica, dada a sua importância para a realização de nossas análises discursivas. Em concordância com Pêcheux, entendemos formação discursiva como "[...] aquilo que pode e deve ser dito" (1995, p. 160). É importante ressaltar que uma formação discursiva é heterogênea a ela mesma, pois, internamente, pode haver oposição de saberes, que gerarão conflitos, contradições e desestabilizações. Por isso, podemos dizer que uma formação discursiva, que é o lugar da constituição do sentido (sua matriz), está em constante movimento e ininterrupta (trans)formação, (re) produzindo-se por meio do interdiscurso.

Cada formação ideológica, por sua vez, constitui:

[...] um conjunto complexo de atitudes e de representações que não são nem "individuais" nem "universais", mas se relacionam mais ou menos diretamente a "posições de classe" em conflito umas com as outras (PÊCHEUX; FUCHS, [1975] 1990, p. 166, grifo dos autores).

Pêcheux e Fuchs elucidam que a noção de formação ideológica caracteriza um elemento suscetível de intervir como uma força de confrontação com outras forças, na conjuntura ideológica, característica de uma formação social em um dado momento.

Nessa linha de raciocínio, podemos dizer, com base em Pêcheux (1995), que o sentido não existe em si, mas é determinado pelas posições ideológicas, em que as palavras são produzidas. Por isso, as palavras adquirem sentido em relação às formações ideológicas nas quais se inscrevem.

Faremos movimentos de ir e vir entre teoria, consulta ao corpus, teoria, com o objetivo de descrever e interpretar a relação do sujeito com sua memória; atravessaremos o efeito de literalidade do sentido e da onipotência do sujeito e investiremos na opacidade da linguagem, no descentramento do sujeito, no efeito metafórico, isto é, no equívoco, na falha, nos deslizes.

Encerramos essa seção ressaltando que contamos com a concordância e anu- 
ência expressa de todos os estudantes, que assinaram o termo de consentimento livre e esclarecido, permitindo-nos analisar as entrevistas, os depoimentos e as produções escritas.

\section{Gestos interpretativos}

$\mathrm{O}$ recorte que mostraremos a seguir refere-se à seção denominada Conclusão de um relatório de estágio elaborado pelo estudante universitário SE14 por ocasião da finalização de um estágio curricular supervisionado, realizado na disciplina Didática Geral.

\section{Recorte número 1 - Produção lin- guística escrita}

Posso agora concluir este relatório, pois apresentamos tudo o que vivemos no longuíssimo e difícil estágio que nos ensinou muitas coisas, como, por exemplo, que os estudantes notam de verdade o que fazemos, o que falamos, o que escrevemos, o que pensamos. Eu no Ensino Médio nunca respondi para professor algum, eu nunca fiz este tipo de coisa no meu Ensino Médio, era diferente. Eu não estudo mas também não dou trabalho, na universidade, vou bem nas provas. Agora, que dou aulas de inglês, que sou monitor, sei que dói quando o aluno é ingrato. Como monitor de disciplina: eu cobro a entrega no dia certo. O educador António Nóvoa afirma que o professor é uma pessoa e parte dessa pessoa é o professor. Concordamos com ele, mas acho que os estudantes deveriam pensar o quanto é difícil ser professor, não é tarefa para qualquer um. Eu me sinto indignado com o que acontece na sala de aula. Então, sou líder de grêmio estudantil, o pessoal se reúne toda semana, eu e eles, a gente tem muito o que dizer sim no relatório. Não acho não que os professores que tive me influenciaram, né? (SE14).

Observamos, inicialmente, que o sujeito estudante parece não ter conseguido planejar sua escrita, sendo fortemente dominado pela afluência dos significantes, sem perceber que as frases estão soltas, desarticuladas, tornando a produção linguística escrita quase que totalmente desconexa. Temos a percepção de que, ininterruptamente, vai escrevendo "sempre para frente", não conseguindo parar, retomar e reler o que escreveu, o que lhe impede de fazer correções e repensar, escutar os sentidos produzidos. Segundo nosso entendimento, o sujeito estudante universitário parece não ter compreendido o que seria um relato acadêmico de atividades de estágio, confundindo-a com relato ou confissão de si.

Seus escritos indiciam dificuldade de afastar-se do texto, para olhá-lo a partir de "outro lugar" (TFOUNI, 2001), o de autor, o que lhe permitiria ocupar uma “[...] posição de autorreflexibilidade crítica no processo de produção de seu discurso" (TFOUNI, 1995, p. 42). Ocupar a posição de sujeito capaz de olhar o texto a partir de outro ponto (lugar) é requisito fundamental para que o sujeito constitua-se como o autor do próprio discurso e, por conseguinte, consiga tecer um intradiscurso em que vigore a ilusão (para o leitor ou ouvinte) de um produto linear, coerente e coeso, que tem começo, meio e fim. 
As marcas da oralidade né, então, sabe bem como o não domínio do intradiscurso indiciam baixo nível de letramento, entendido aqui como "[...] um processo cuja natureza é sócio-histórica [sic]" (TFOUNI, 1995, p. 31). Para Tfouni (1994), colocar-se como autor do próprio discurso é a noção-eixo do conceito de letramento, enquanto processo socio-histórico. É pertinente dizer ainda que essa pesquisadora propõe um continuum, a partir do qual podemos observar graus ou níveis de alfabetização e de letramento.

No caso de relato acadêmico de estágio, é esperado que o sujeito relate e descreva acontecimentos por ele vivenciados, analisando-os e tecendo reflexões, tanto à luz da literatura específica indicada e disponibilizada pelo docente responsável pela disciplina, quanto pela decorrente de pesquisas feitas pelo próprio estudante. $\mathrm{O}$ sujeito estudante insere-se em formações discursivas nas quais predomina o discurso narrativo, um lugar privilegiado para a elaboração da experiência pessoal, transformação do real em realidade e organização da simbolização particular do sujeito (TFOUNI, 1995).

Podemos observar, no recorte número 1, várias posições de sujeitos, a partir das quais o sujeito enuncia; SE14 enquanto aluno do ensino médio: "eu nunca fiz este tipo de coisa no meu ensino médio, era diferente"; SE14 enquanto estudante universitário: "eu não estudo mas também não dou trabalho, vou bem nas provas"; SE14 enquanto líder de grêmio estudantil: "o pessoal se reúne toda semana, eu e eles, a gente tem muito o que dizer sim no relatório"; SE14 enquanto monitor de disciplina: "eu cobro a entrega no dia certo".

Ora o eu é aluno do ensino médio, ora estudante universitário, ora monitor, ora professor particular de língua estrangeira. Temos a percepção de que é construída, tecida, uma rede de relações imaginárias na qual estão presentes múltiplas identificações.

De toda forma, é possível observar que, no trecho citado, os dizeres de SE14 indiciam a necessidade de falar de si, de se dizer, a partir de diferentes posições de sujeito com as quais se identifica, embora negue que várias das experiências por ele destacadas lhe são constitutivas. Tanto o constituem, que ele as rememora, para, em seguida, denegá-las.

Birman (2003) observa que a subjetividade na cultura do narcisismo é marcada pela impossibilidade de descentramento de si mesmo, em que o sujeito vive permanentemente em um registro especular, por isso o sujeito nega essa constituição.

Isso nos permite dizer que, mesmo que tente negar ou que acredite ser possível negar, o sujeito se vê sempre a partir do olhar do outro, ou como nos ensina Coracini: “[...] o tempo todo falamos ou escrevemos sobre nós mesmos, mesmo quando falamos do(s) outro(s), que, em última instância, nos constituem" (2003, 
p. 3). Em relação a essa afirmativa, vale citar o psicanalista Fédida, que diz:

[...] o olho não pode ver a si próprio e só encontra sua imagem num outro olhar, pois olho é espelho, mas não de si mesmo; o espelho simultaneamente reúne o mesmo e o Outro (1988, p. 45).

É interessante notar que, ao final do texto, o SE14 parece desconfiar de que sua escrita só avança e prossegue, sem parada ou retomada alguma, consistindo em um discurso caracterizado por queixas, a respeito da indisciplina dos alunos integrantes da turma em que realizou o estágio, das condições de produção do ensino na escola, do não aprendizado dos estudantes, das ações dos gestores.

Com relação a esse aspecto do mal-estar expresso por SE14, recorremos a Freud (2006). Segundo o psicanalista, a civilização é construída pela abdicação dos instintos, e essa desistência gera mal-estar, condição inerentemente humana. No cotidiano escolar - local que, como instituição legitimada, procura abafar, silenciar esse desconforto -, a escola torna-se o próprio mal-estar, manifesto na negação dos assuntos pedagógicos e, em seu lugar, acaba por prevalecer o discurso da queixa.

A estratégia de SE14 para dizer que percebe que usou o espaço mais para dizer de si e de suas queixas e menos para descrever e analisar as ações didáticas por ele desenvolvidas em sala de aula consiste em colocar um P.S. (post scriptum) ao final da página:
[...] eu falei muito aqui, e parece que não posso escrever isso aqui, só lá na supervisão, com a supervisora pode, aí, lá, eu posso falar mesmo. Mas, olha, eu prestei vestibular e fui muito bem aprovado, minha redação era diferente, era organizada, tinha tudo (SE14).

Parece-nos que o sujeito estudante inscreve-se em uma formação discursiva que lhe faz acreditar na existência de dois distintos espaços: o aqui (texto) e o lá (supervisão). O espaço daqui, do texto, é imaginado como restrito, passível de censura: "não posso escrever isso aqui", entendida aqui como "[...] interdição da inscrição do sujeito em formações discursivas determinadas" (ORLANDI, 1992, p. 107). Entretanto, apesar de se imaginar censurado, esse sujeito cindido, fragmentado, esfacelado, fala de si mais do consegue pressupor ou imaginar.

Se o espaço do texto é marcado pela interdição ao poder dizer, o espaço da supervisão, por sua vez, parece oferecer, ilusoriamente, ao sujeito oportunidades de plena satisfação, de prazer absoluto. Ilusórios porque, enquanto sujeitos desejantes, atravessados pelo inconsciente, somos sempre "[...] um projeto inacabado, produzindo-nos de maneira interminável" (BIRMAN, 1997, p. 34).

Nossa argumentação pode ser adensada se convocarmos uma das mais importantes contribuições lacanianas: o objeto $a$. De acordo com o psicanalista Quinet, o objeto $a$ é "[...] aquilo atrás do 
qual passamos a vida correndo" (2012, p. 34), e

[...] trata-se de um objeto sempre em alteridade para o sujeito do desejo que $o$ 'encontra' no pequeno outro, seu semelhante, como aquilo do parceiro que lhe desperta desejo e lhe dá prazer (2012, p. 34).

A sequência discursiva: "lá na supervisão, com a supervisora pode, aí, lá, eu posso falar mesmo", ilustra bem nossa afirmação, especialmente os significantes "supervisão-supervisora" que, a nosso ver, tomam a forma desse objeto perdido, $a$.

A psicanálise freudo-lacaniana nos ensina que, no inconsciente, como discurso do Outro, sempre haverá de faltar significantes; jamais encontraremos "o" significante ideal, exato, que daria sentido último à nossa vida, às nossas perguntas, angústias e histórias. Como consequência disso, a cadeia significante que compõe o inconsciente acaba sendo infinita, pois sempre desejaremos e poderemos agregar um significante a mais, e falar, falar e falar, na vã tentativa de satisfazer o desejo de fazer sentido. Desejo impossível de ser satisfeito, que nos faz servos da linguagem.

A seguir, apresentamos a reescrita do texto apresentado no recorte número 1.

Recorte número 2 - Reescrita - texto 1 Para concluir este relatório, destacamos que o longo estágio nos ensinou muitas coisas, dentre elas, a de que os estudantes notam o que fazemos, escrevemos e pensamos. Somos, assim, por eles avaliados. Outro aprendizado é o que diz respeito à impossibilidade de separar o eu pessoal do eu profissional, pois essas duas dimensões do sujeito são inseparáveis. Como diz o educador português, António Nóvoa (1992, p. 9): “(...) o professor é uma pessoa e parte dessa pessoa é professor".

Considerando o que acima expusemos, queremos dizer que as diferentes experiências que tivemos como estudante, como líder de grêmio estudantil, como monitor de disciplina contribuíram para que compreendêssemos que o estágio, ao contrário do que supúnhamos, não é atividade prática apenas, mas também teórica, porque instrumentalizadora da práxis docente, entendida esta como "atividade de transformação da realidade" (PIMENTA, 2014, p. 44) (SE14, grifo nosso).

Observamos, inicialmente, um texto coerente, que traz parágrafos articulados e coesos, indícios de que o estudante conseguiu olhar para o seu texto com base em outra perspectiva, o que lhe permitiu analisar sua produção e identificar trechos que poderiam ser reescritos.

Olhar para o próprio texto, a partir de outra perspectiva, foi possível graças às várias releituras do texto em questão, inicialmente realizadas individualmente e em silêncio pelo sujeito estudante universitário. A cada uma delas, ele anotava, à margem da folha, suas observações, suas críticas e os trechos que deveriam ser reescritos de acordo com sua análise. A prática individual da leitura silenciosa foi feita durante os encontros presenciais do curso de extensão universitária Práticas de Reescrita. Tais leituras exigiram que o estudante aprendesse a concentrar-se nos seus escritos, de modo 
a se ater a eles, exclusivamente, sem interferências outras, como conversas em redes sociais, em aplicativos inseridos em aparelhos móveis, dentre outras atividades diversas.

Reler, retomar, revisar o próprio texto são ações possíveis porque o sujeito se coloca na perspectiva do dizível, da memória. $\mathrm{O}$ conceito de memória é relevante para o presente trabalho, pois partimos do pressuposto de que tanto a escrita quanto a reescrita são formadas por enunciados que não vêm apenas de um imaginário "ponto de origem" ou "ponto de partida", mas, sim, de enunciados provenientes de outros discursos. Assim, o dizer não é propriedade particular do sujeito, as palavras não são exclusivamente suas, visto que significam pela história e pela língua. Dessa forma, o que já foi dito em outro lugar, sentidos já formulados e enunciados continuam ecoando em suas palavras, produzindo significados.

Cumpre esclarecer que, de acordo com o enfoque discursivo, entendemos a memória social como "aquela que é inscrita no seio das práticas discursivas" (COURTINE, 1981, p. 45). Não se trata, portanto, de memória de um ponto de vista psicológico ou cognitivo.

Para dialogar com Courtine, mobilizamos Pêcheux, que afirma que:

[...] uma memória não poderia ser concebida como uma esfera plena, cujas bordas seriam transcendentais históricos e cujo conteúdo seria um sentido homogêneo, acumulado ao modo de um reservatório: é necessariamente um espaço de desdobramentos, de réplicas, polêmicas e contra-discursos (1999, p. 10).
É a memória que nos permite reconhecer, na reescrita, efeitos de reprodução, de deslocamentos ou de transformações de sentidos, pois todo dizer encontra-se na confluência dos dois eixos, o da memória (constituição) e o da atualidade (formulação).

No processo de reescrita, o sujeito está submetido, inconscientemente, tanto a uma memória social quanto à memória discursiva (memória particular), memórias que o conduzem a um determinado gesto interpretativo, e esse, por sua vez, estabelece a predominância de um sentido em detrimento de outros, fazendo parecer, em alguns casos, que $o$ sentido escolhido é o único possível.

Dando prosseguimento, assinalamos que o processo de leituras e releituras teve um segundo momento, quando aconteceram leituras e releituras do texto 1 , no âmbito coletivo, ou seja, o texto foi lido em voz alta pelo sujeito estudante universitário para o grupo de estudantes cursistas, que opinaram sobre o que poderia ser acrescentado, suprimido, alterado, substituído. $\mathrm{O}$ sujeito estudante vai, assim, constituindo-se também a partir das vozes desses sujeitos, que vão tecendo a sua subjetividade. Longe de fixarem ou estabilizarem suas características, transformam-no em um sujeito em processo de ininterrupta transformação.

$\mathrm{E}$, por fim, houve leituras e releituras em voz alta, feitas pelo sujeito estudante universitário, para o docente responsável pelo curso, momento em que foram realizadas interrupções, per- 
guntas, análises e sugestões de parte do docente a cada trecho considerado passível de ser reescrito. Essas leituras em voz alta e as respectivas intervenções do docente foram gravadas em áudio e, posteriormente, escutadas pelo sujeito estudante. A prática de escutar-se, ou seja, escutar a gravação de sua própria voz lendo a produção textual escrita realizada fez com que outros efeitos de sentidos fossem produzidos. Assim, na terceira etapa desse processo, o próprio estudante já conseguia identificar o que denominou de "passagens sem nexo" no texto por ele escrito.

Nessas condições favoráveis de produção, as leituras e as releituras deram origem à reescrita em análise. A reescrita, nesse sentido, é a materialização das leituras e releituras feitas por um sujeito estudante universitário que ocupa também a posição de leitor de seus próprios textos, em diferentes condições de produção: ora os lê individualmente e registra suas próprias observações, ora os lê para um público constituído por estudantes cursistas, ora para o docente responsável pelo curso de extensão.

Gostaríamos de ressaltar que a leitura, na perspectiva discursiva, é uma questão de natureza, de condições, de modos de relação, de trabalho, de produção de sentido, enfim, de historicidade (ORLANDI, 1996). O leitor, por sua vez, não apreende um sentido que supostamente estaria colado às palavras, mas ele produz e atribui sentidos, como nos ensina Orlandi (1996). É dentro dessa reflexão que a estudiosa afirma que toda leitura tem sua história, o que explica o fato de que leituras que são possíveis para um mesmo texto em certas épocas, não o foram em outras, e leituras que não são possíveis hoje poderão ser no futuro. Segundo Orlandi (1996), lemos diferentemente um mesmo texto em épocas distintas e sob condições diferentes.

Nessa linha de pensamento, podemos pensar também que reescritas possíveis para um texto em determinado momento podem não ser possíveis em outro, o que nos permite dizer, a exemplo do que diz Orlandi (1996) sobre a leitura, que toda reescrita tem sua história. Isso porque a reescrita também é um efeito de historicidade.

Retomando a análise, gostaríamos de salientar que, para Tfouni (2001), a autoria está relacionada com um processo descrito por Authier-Revuz (1982) como de ajuste perfeito entre as palavras e $o$ real, que sempre escapa. $O$ texto a ser produzido não deve admitir lapsos, devendo o autor controlar as formações do inconsciente, as chamadas parapraxias.

Atentando-nos à reescrita, podemos notar ausência de lapso, o que nos mostra que o sujeito estudante não rompeu a estrutura linear do discurso (o intradiscurso) e, portanto, não comprometeu a unidade ilusória do texto. Podemos identificar também indícios linguístico-discursivos, como os pronomes elas, eles, além das expressões para concluir, outro aprendizado, considerando o que acima expusemos, que nos permitem dizer que o sujeito 
estudante retroagiu sobre o processo de produção de sentidos, "[...] procurando 'amarrar' a dispersão que está sempre se instalando, devido à equivocidade da língua" (TFOUNI, 2001, p. 83). Segundo Tfouni, "[...] o autor produz aquilo que Lacan [...] denominou de point de capiton, ponto de estofo" (2001, p. 83). Trata-se de lugares do processo de enunciação em que se percebe que o sujeito efetuou um movimento de retorno ao enunciado, podendo olhá-lo de um outro lugar, que, conforme já assinalado, foi chamado por Tfouni (2001) "lugar do autor".

Com base nos argumentos elencados, entendemos que a reescrita produzida pelo sujeito estudante universitário traz indícios de emergência de autoria, o que, a nosso ver, constitui lugar importante para essa posição de sujeito que, em breve, deverá ocupar a posição de professor.

Dando sequência, apresentaremos dois recortes que trazem depoimentos escritos de um sujeito estudante (SE37), a respeito de sua relação com a escrita bem como a respeito dos sentidos atribuídos à prática da reescrita.

Recorte A

Para mim, escrever é uma droga, sempre foi, motivo de desgosto, sempre tive receio, medo, pavor, fugia das redações na escola, ensino fundamental, ensino médio... angústia total... Escrever não é fácil para ninguém, ainda mais para mim que vim das exatas para a Pedago... Mas, quando dá pra falar da gente, aí dá para escrever... Mas na Pedago, isso não pode, só legislações e metodologias de ensino, você também acha, concorda? (SE37, grifo nosso).
Iniciamos nossa análise destacando que SE37 inscreve-se em formações discursivas que lhe fazem acreditar que "escrever é uma droga". Interessante destacar a ambiguidade do enunciado, sobretudo, se tivermos em mente as reflexões de Derrida (1991) a respeito da escrita. De acordo com o filósofo, a escrit(ur)a é pharmakon, isto é, remédio e veneno, ao mesmo tempo. Pensar sobre a escrita requer considerar seus benefícios e malefícios, considerando que se interpenetram; não são excludentes, portanto.

Em relação aos benefícios da escrita, segundo nosso entendimento, podemos pensar que ela pode ser um espaço no qual o sujeito "fala de si", servindo de catarse, de possibilidade de o escritor nela expor emoções, sentimentos, percepções, sua subjetividade enfim. Escrever pode trazer consolo, alívio, permitindo, também, a expressão de fantasias e devaneios do sujeito. O enunciado "quando dá pra falar da gente, aí dá para escrever" (SE37) ilustra bem essa afirmação.

É possível escrever porque o "falar de si" surge de uma necessidade ou interesse, ou seja, da expressão de um desejo. Tal necessidade nem sempre é valorizada pela escola, na qual, enquanto instituição, em muitos casos, há a preocupação fundamental de ensinar as convenções da escrita, esquecendo-se de que o contexto e as condições de produção são constitutivos do sentido, de que não há sentidos literais, transparentes ou neutros. A escola desconsidera a possi- 
bilidade de multiplicidade de sentidos bem como o fato de que a sedimentação histórica dos sentidos ocorre porque, em condições de produção determinadas, um sentido acaba por adquirir estatuto dominante em relação aos outros.

Ainda nessa linha de raciocínio, gostaríamos de ressaltar que a escola tradicional, em algumas situações, ainda se prende às ideias de estabilidade, homogeneidade e linearidade do sistema da língua, caras à linguística estruturalista. Nessas condições de produção, a memória discursiva do sujeito educando e os sentidos aos quais se filia e, portanto, lhe afetam não são mobilizados, sequer considerados, o que acaba por desmotivá-lo a realizar produções textuais, inclusive as orais.

Retomando a discussão a respeito do "falar de si", salientamos que se trata de um recurso exequível para a escola possibilitar a emergência da subjetividade do educando, e também para a autoria, pois:

[...] o sujeito busca, sobretudo na escrita de si, uma maneira de construir sua identidade, através da memória e das relações de identificação com o outro, num constante movimento entre a singularidade e a alteridade" (AGUSTINI; GRIGOLETTO, 2008, p. 146).

Observamos que a sequência encadeada dos significantes medo, pavor e horror produz efeito de sentido de gradação, ou seja, parece-nos que os sentimentos negativos vinculados à escrita foram se intensificando, à medida que os anos de escolarização foram progredindo, culminado com o sentimento por ele identificado como de "angústia total".
Produzir um texto é um ato de inscrição em uma superfície vazia (papel em branco, tela de computador), sendo que, por meio desse ato, deixamos um pouco de nós. Não por acaso, o sentimento de angústia do sujeito estudante universitário concentra na sequência discursiva "angústia total" todos os sentimentos aversivos em relação à escrita.

Em Inibições, sintomas e angústia: um estudo autobiográfico, escrito por Freud em 1925 e publicado em 1926, podemos encontrar importante definição de angústia: "[...] atitude do eu que põe em movimento os mecanismos de defesa" (FREUD, 2010, p. 124). Fundamentados na leitura e nos estudos do texto citado, podemos dizer que a angústia surge como uma reação a um estado de perigo, reproduzindo-se sempre que um estado dessa natureza se repete. Trata-se de uma sensação que "tem acentuado caráter de desprazer”, explica Leite (2011, p. 53), psicanalista brasileira.

É pertinente assinalar que, nesse mesmo texto, o autor vienense recupera dois de seus clássicos casos $O$ pequeno Hans e $O$ homem dos lobos, para afirmar que "[...] em ambos os pacientes a força motriz da repressão (recalque) era o medo da castração". Com base nessa afirmativa, surge o axioma freudiano: "toda angústia é a angústia da castração" (FREUD, 2010, p. 124).

Para complementar e adensar nossos argumentos, recorremos a Lacan (2004), para quem o fenômeno da angústia terá estatuto de afeto. $\mathrm{O}$ psicanalista francês 
assinala que a angústia é o encontro com o abismo, emergindo quando, em dado momento, não temos respostas às questões: $\mathrm{O}$ que o outro quer de mim? O que sou para o outro? A angústia em Lacan (2004) é proposta a partir de um não saber fazer diante da falta do $\mathrm{Ou}$ tro. O sentimento de angústia implica o sujeito no e com o mais íntimo de si mesmo. Nessa linha de argumentação, lembramos que "[...] o surgimento da angústia é sinal do desaparecimento momentâneo de toda referência identificatória" (LEITE, 2011, p. 71).

Retomando as SDRs, do recorte A, trazemos o enunciado "Mas na Pedago, isso não pode", que, para nós, produz o efeito de sentido de censura, mas, também, de ausência de identificação entre o que é proposto institucionalmente no curso de licenciatura em pedagogia, ou seja, legislações e metodologias de ensino, e entre o que o estudante espera e deseja: possibilidade de "falar de si".

Considerando nossa experiência como docentes do ensino superior e tendo em vista outras pesquisas por nós conduzidas sobre a escrita nesse nível de ensino, é possível observar número importante de estudantes de graduação que vivenciam o sentimento de angústia em relação à escrita. A nosso ver, a escola poderia movimentar-se no sentido de oferecer condições favoráveis de produção para que o estudante aprendesse a produzir textos acadêmicos, orais e escritos. Para tanto, temos defendido o que denominamos de "espaços discursivos", espaços físico-discursivos, destinados a receber estudantes que aderem espontaneamente a projetos relacionados às práticas de (re)leitura, escrita e (re) escrita. Esses espaços foram por nós concebidos e implementados no âmbito de uma universidade pública paulista, por meio de cursos de extensão universitária, sendo um deles o Práticas de Reescrita, descrito anteriormente.

Esses espaços discursivos, que já receberam cerca de 120 alunos, foram concebidos com base nos estudos, postulados e contribuições da pesquisadora Coracini, que nos diz:

[...] é preciso que o aluno tenha a possibilidade de se dizer, mais do que dizer, de se expor, mais do que expor para que vivencie a experiência do estranhamento (unheimlichkeit) a construção de si, de uma identidade ilusória, mas necessária para o equilíbrio do sujeito neurótico, um sentimento de unidade, de completude, reunindo fragmentos, traços que constituem uma subjetividade clivada, esgarçada, não raro sofrida (CORACINI, 2010, p. 46).

Outra possibilidade de oferecer ao estudante universitário condições favoráveis de produção para que possa expressar sua subjetividade diz respeito à incorporação dos discursos lúdico e polêmico nos planos de curso de pedagogia. O discurso lúdico promove a inserção do sujeito em formações discursivas caracterizadas pela multiplicidade de sentidos, podendo levá-lo a aprender a "brincar" com a linguagem, expressar suas fantasias e devaneios e, dentro disso, escrever sem censura e interdição alguma. Como consequência, muitos 
sentidos calados e silenciados poderiam vir à tona, emergir e circular em sala de aula. O discurso polêmico, por sua vez, instaura a discussão, o debate, a luta pelo objeto, o que promove o deslocamento da posição ouvinte, ocupada pelo estudante, sobretudo quando vigora o discurso pedagógico escolar tradicional que, em alguns casos, constitui-se com traços autoritários e insiste em colocar o sujeito-educando na posição de um sujeito incapaz de refutar, discordar, contra-argumentar. Trazer o discurso polêmico para a sala de aula poderia contribuir para com o deslocamento de sentidos prefixados bem como para a produção dos novos. Em ambos os casos, trabalhar-se-ia com a estrutura e com o funcionamento da linguagem, visto que esses aspectos problematizam a falha, o equívoco e os deslizamentos de sentidos, constitutivos da linguagem, mas, também, a sua historicidade e funcionamento ideológico.

Avançando, trazemos o recorte B, com o depoimento do sujeito estudante universitário 37, a respeito da experiência com a prática da reescrita.

\section{Recorte B}

Poder reescrever textos me deixou menos aflito, menos angustiado, porque percebi que posso fazer outras versões, que vão aos poucos aprimorando o texto (SE37, grifo nosso).

De acordo com as nossas interpretações, a prática da reescrita pode ter mesmo deixado o sujeito estudante universitário menos aflito, menos angus- tiado, porque lhe permitiu ressignificar sua relação com a escrita que, como mostrado no recorte $A$, era marcada fundamentalmente por sentimentos de raiva e aversão a essa prática cultural.

Vimos defendendo a reescrita como possibilidade de ressignificação, entendida aqui a partir do conceito de après-coup, que é a tradução francesa para o conceito freudiano de nachträglichkeit (substantivo cuja tradução significa "posteridade"), e nachträglich (que significa "posterior" e "posteriormente", na língua alemã).

É pertinente destacar que não há artigo algum escrito por Freud centrado especificamente nesse conceito, conforme explica Faimberg (2008). A autora assinala que os créditos devem ser concedidos ao psicanalista Lacan, que, em 1953, ressalta a relevância desse termo, tomando especificamente como referência principal o caso homem dos lobos (FREUD, 1969).

Recorrendo a Laplanche e Pontalis (2001), compreendemos que a noção de après-coup é importante para a concepção psicanalítica de temporalidade, visto que estabelece uma relação complexa e recíproca entre um evento importante e sua ressignificação posterior, por meio da qual o evento adquire uma nova eficácia psíquica.

Os conflitos e acontecimentos traumatizantes podem, portanto, ser ressignificados, de acordo com o que nos ensinam Freud (1969) e Faimberg (2008), possibilitando, assim, ao sujeito atravessado por determinações inconscientes ocupar 
outros lugares, a partir dos quais outras interpretações poderão ser (re)formuladas. É nessa linha de raciocínio que entendemos que o reescrever possibilita ao sujeito ressignificar sentidos, visto que, em momento posterior, o sujeito pode (re)tomar seus escritos, repensá-los e interpretá-los a partir de um outro e novo lugar, bem como dos sentidos de sua memória discursiva, que são atualizados e reconstruídos na enunciação, conforme Achard (1999).

Outro aspecto decorrente da ressignificação tem a ver com o fato de que é possível ao sujeito singularizar-se no processo de escrita, pois lhe é permitido (se) dizer e (se) colocar, a partir de sua memória particular de sentidos, o que contribui para que o sujeito se coloque como autor de seu próprio dizer.

É importante assinalar que, segundo nossa compreensão, é tarefa do ensino superior, em especial dos cursos de licenciatura, criar condições favoráveis de produção para que o sujeito estudante possa se descolar do lugar de um sujeito que se sente incapaz para o de um sujeito que se entenda provido de recursos e de condições para (re)ler, (re)interpretar, (re)escrever o texto. Para tanto, é desejável que seja considerado o "nível de letramento" do sujeito (TFOUNI, 1995).

De acordo com Tfouni (1995), as práticas sociais letradas influenciam todos os indivíduos de uma sociedade. Sendo assim, todos os sujeitos, mesmo os não alfabetizados, têm saberes sobre a escrita, que é o letramento. A proposta do continuum por ela edificada permite-nos observar níveis de letramento nas produções linguísticas orais e escritas, tanto nas produções das crianças quanto nas dos jovens e adultos. É possível notar que existem níveis variados de letramento, inclusive sem a presença da alfabetização. Esses níveis dependem dos conhecimentos dos sujeitos a respeito da escrita e das suas condições para se colocarem como autores de seus próprios dizeres, o que pode se efetivar tanto no discurso oral quanto no discurso escrito. A interpenetração desses discursos é observada e considerada como critério quando na análise dos níveis de letramento.

No caso das produções linguísticas escritas, realizadas por sujeitos estudantes universitários, é possível observar que, em alguns casos, apesar de terem sido aprovados no vestibular de uma importante universidade pública e cursarem o ensino superior, alguns indivíduos, já nas etapas finais do curso, ainda demandam saberes importantes sobre a língua escrita, em particular os da escrita acadêmica.

É nesse sentido que decorre a relevância da prática da reescrita, visto que considera o nível de letramento do sujeito e o ajuda a avançar a partir desse nível, quer seja lhes ensinando a reler e a escutar os seus próprios escritos, quer seja lhes mostrando que não há número final ou exato de versões para um texto, ou lhes incentivando a romper com o silêncio dos sentidos ao qual são submetidos, em alguns casos, considerando a subjetividade do sujeito e 
a prática da reescrita, contribuindo para que o sujeito ressignifique os sentidos de sua relação com a escrita. Assim sendo, podemos afirmar que aprendizagem da reescrita "[...] se dá de forma processual, constituindo-se etapa por etapa, tecendo-se fio por fio" (SCHONS, 2005, p. 142).

Por fim, é pertinente enfatizar o papel e a responsabilidade dos cursos de graduação em pedagogia, que formam professores. Trabalhar para que os estudantes aprendam a lidar com os "saberes da alteridade" (CIFALI, 1998), ou seja, com os saberes necessários para a compreensão de que o sujeito se constitui em sua relação com o outro-Outro e em sua relação com aquilo que está fora de si.

\section{Considerações finais}

Procuramos mostrar neste trabalho que a prática da reescrita, quando realizada em condições favoráveis de produção, possibilita ao sujeito retomar, reler, reorganizar e modificar o já-dito, produzindo a ilusão de originalidade, o que pode contribuir para a instauração de um processo de autoria.

As condições favoráveis de produção envolvem possibilidades de o sujeito realizar diferentes (re)leituras de suas produções escritas e perceber os efeitos de sentido que podem emergir a partir do modo como organizou o texto. Essas condições envolvem, também, o que vimos denominando de "escuta sensível", escuta que requer a compreensão de que o discurso mantém sempre a relação com outros dizeres, sendo produzido em um espaço de redes de filiações socio-históricas de sentido; não se trata de uma entidade homogênea, portanto. Requer, ainda, o entendimento de que o sujeito se constitui na relação com o outro-Outro, na interlocução com o meio socio-histórico.

O trabalho com a prática da reescrita mostra que tanto a escrita como a reescrita são espaços dos quais o sujeito se vale para falar de si, expor sentimentos e emoções recônditos, em alguns casos, denegados. Nesse falar de si, o sujeito diz além do que imagina, pois "um algo a mais" é sempre dito, para além da linearização do dizer. Esse "algo a mais", que é da ordem do inconsciente, é impossível de ser apreendido. Podemos dizer que o inconsciente, essa cadeia de significantes sobre os quais não se tem controle, é o lugar privilegiado da subjetividade e, também, do discurso do Outro, que antecede a própria existência do sujeito. E é a esse Outro que ele tem de se assujeitar para se constituir como sujeito. Nesse embate com os significantes e com o Outro como linguagem, tesouro do significante, estranho e estrangeiro a mim mesmo, o sujeito se perde, se aliena, mas também se singulariza.

A prática da reescrita possibilita ao sujeito subjetivar-se e, nesse processo, o sujeito se vê às voltas com a falta que o constitui bem como com a alteridade, com as vozes que atravessam e ecoam na sua voz. Lidar com a alteridade nem sempre é tarefa fácil, sobretudo se ti- 
vermos em mente que os sujeitos com os quais trabalhamos são jovens, que falam a partir da posição de estudantes universitários.

Nessa perspectiva, entendemos que os cursos de graduação em pedagogia não podem e não devem fugir da possibilidade de incorporar ao currículo das disciplinas eixos que permitam conhecimento, análise, reflexão, tanto da subjetividade quanto dos 'saberes da alteridade' do educando. Talvez, a partir dessas incorporações pudéssemos dar um passo importante, rumo à formação de sujeitos que sabem um pouco de si, condição fundamental para a docência responsável.

\section{Rewriting practices:} possibilities of instauration of authorship

\begin{abstract}
We hereby present the results of a concluded research, which investigated the practices of rewriting as a possibility of instauration of authorship in academic texts produced by college students. We also present results concerning the relationship those students establish with the writing and the possibilities of reinterpretation of such symbolic object from rewriting. The theoretical framework that supports this investigation consists of Discourse Analysis Pêcheuxtiana, Freudian-Lacanian Psychoanalysis and contributions of Educational Sciences, in particular those relating to teacher training. Among the conclusions reached, we highlight
\end{abstract}

those that indicate that (re)writing constitutes an alternative to the subject "talk about themselves", subjectify themselves and learn to deal with their otherness. Another conclusion concerns the understanding that the rewrite, when performed in adequate conditions of production, enables the emergence of authorship.

Keywords: Rewrite. Subjectivity. Otherness. Authorship. University.

\section{Nota}

1 Gilgamesh, rei de Uruk, atual Mesopotâmia. $\mathrm{O}$ inquieto rei só conseguiu apaziguar sua busca incessante pela imortalidade quando gravou em uma pedra toda a sua história. A lenda traz a metáfora da escrita como forma de vencer o medo da morte, posto que garante a permanência no tempo daquele que escreve, (TFOUNI, 1994).

\section{Referências}

ACHARD, P. Memória e produção discursiva de sentido. In: ACHARD, P. et al. Papel da memória. Campinas: Pontes, 1999. p. 11-17.

AGUSTINI, C. L. H.; GRIGOLETTO, E. Escrita, alteridade e autoria em análise de discurso. Matraga, Rio de Janeiro, v. 15, n. 22 , p. 145-156, jan./jun. 2008.

AUTHIER-REVUZ, J. Heterogeneidade(s) enunciativa(s). Caderno de Estudos Linguísticos, Campinas: IEL/Unicamp, v. 19, p. 25-42, 1990.

. Hétérogénéité montrée et hétérogénéité constitutive: élements pour une approche d'autre dans le discours. DRLVA Revue de linguistique, Paris, n. 26, p. 91151, 1982.

BIRMAN, J. Estilo e modernidade em psicanálise. São Paulo: Editora 34, 1997. 
. Mal-estar na atualidade: a psicanálise e as novas formas de subjetivação. Rio de Janeiro: Civilização Brasileira, 2003.

CIFALI, M. Démarche clinique, formation et écriture. In: PAQUAY, L. et al. Former des enseignantes professsionnels. Quelles stratégies? Quelles compétences? 2. ed. Bruxelles: De Boeck Université, 1998. p. 119-136.

CORACINI, M. J. R. F. Discurso e escrit(ur) a: entre a necessidade e a (im)possibilidade de ensinar. In: ECKERT-HOFF, B.; CORACINI, M. J. R. F. (Org.). Escrit(ur)a de si e alteridade no espaço papel tela. Campinas: Mercado de Letras, 2010. p. 17-30.

. Subjetividade e identidade do(da) professor(a) de português. In: CORACINI, M. J. R. F. (Org.). Identidade e discurso: (des)construindo subjetividades. Campinas: Unicamp; Chapecó: Argos, 2003. p. 239-255.

COURTINE, J. J. Analyse du discours politique. In: Language, Larouse, n. 62, p. 6-127, 1981.

DERRIDA, J. A farmácia de Platão. 3. ed. São Paulo: Iluminuras, 1991.

FAIMBERG, H. Après-Coup. In: TANIS, B. Livro anual de psicanálise. São Paulo: Escuta, 2008. p. 11-16.

FIAD, R. Reescrita de textos: uma prática social e escolar. Organon, Porto Alegre, n. 46 , p. 147-159, jan./jun. 2009.

FÉDIDA, P. Nome, figura e memória: a linguagem na situação psicanalítica. São Paulo: Escuta, 1988.

FOUCAULT, M. A escrita de si. In:

$O$ que é um autor. 5. ed. São Paulo: Veja Passagens, 1992. p. 128-160.

Ditos \& escritos V: ética, sexualidade e política. Rio de Janeiro: Forense Universitária, 2004.

FREUD, S. História de uma neurose infantil (1914-1918). Rio de Janeiro: Imago, 1969. (Edição standard brasileira das obras psicológicas completas de Sigmund Freud, v. XVII).
Inibição, sintoma e angústia: um estudo autobiográfico (1926). Rio de Janeiro: Imago, 2010. (Edição standard brasileira das obras psicológicas completas de Sigmund Freud).

O Eu e o Id, "Autobiografias" e outros textos (1923-1925). São Paulo: Companhia das Letras. 2011. (Obras Completas, v. 16).

. O mal estar na civilização (1930 [1929]). Rio de Janeiro: Imago, 2006. (Edição standard brasileira das obras psicológicas completas de Sigmund Freud, v. XX).

GINZBURG, C. Sinais: raízes de um paradigma indiciário. In: Mitos, emblemas, sinais: morfologia e história. São Paulo: Companhia de Letras, 1989. p. $143-179$.

GRIGOLETTO, E. A construção da identidade na escrita de si: do ambiente universitário à internet. Desenredo, Passo Fundo, v. 2, n. 2, p. 203-223, jul./dez. 2006.

LACAN, J. Escritos. Rio de Janeiro: Jorge Zahar, 1998. (Originalmente publicado em 1966).

O seminário Livro 10: A angústia. Rio de Janeiro: Zahar, 2004.

O seminário Livro 11: os quatro conceitos fundamentais da psicanálise. Rio de Janeiro: Zahar, 1988.

O seminário Livro 18: de um discurso que não seria semblante. Rio de Janeiro: Jorge Zahar, 2009. (Originalmente publicado em 1971).

LAPLANCHE, J.; PONTALIS, J. B. Vocabulário de psicanálise. São Paulo: Martins Fontes, 2001.

LEITE, S. Angústia. Rio de Janeiro: Zahar, 2011.

MACHADO, A. M. N. Presença e implicações da noção de escrita na obra de Jacques Lacan. 2. ed. Ijuí: Unijuí, 2000.

ORLANDI, E. P. A linguagem e seu funcionamento. Campinas: Pontes, 1987. 
. Análise de discurso: princípios e procedimentos. Campinas: Pontes, 1999.

. As formas do silêncio no movimento dos sentidos. Campinas: Unicamp, 1992.

Cortez, 1996.

Discurso e leitura. 3. ed. São Paulo:

PÊCHEUX, M. O papel da memória. In: ACHARD, P. (Org.). O papel da memória. Campinas: Unicamp, 1999. p. 49-56.

. Semântica e discurso: uma crítica à afirmação do óbvio. Campinas: Unicamp, 1995.

PÊCHEUX, M.; FUCHS, C. A propósito da análise automática do discurso: atualização e perspectivas. In: GADET, F.; HAK, T. (Org.). Por uma análise automática do discurso. Campinas: Unicamp, 1990. p. 163-252. (Originalmente publicado em 1975).

QUINET, A. Os outros em Lacan. Rio de Janeiro: Zahar, 2012.

SCHONS, C. R. Escrita, efeito de memória e produção de sentidos. In: SCHONS, C. R.; ROSING, T. M. K. (Org.). Questões de escrita. Passo Fundo: UPF Editora, 2005. p. 138-156.

TFOUNI, L. V. A dispersão e a deriva na constituição da autoria e suas implicações para uma teoria de letramento. In: SIGNORINI, I. (Org.). Investigando a relação oral / escrito e as teorias do letramento. Campinas: Mercado de Letras, 2001. p. 67-94.

A escrita-remédio ou veneno? In: AZEVEDO, M. A.;MARQUES, M. L. (Org.). Alfabetização hoje. São Paulo: Cortez, 1994. p. 57-77.

Letramento e alfabetização. São Paulo: Cortez, 1995.

Letramento e autoria - uma proposta para contornar a dicotomia oral e escrita. Revista da ANPOLL: Associação Nacional de Pós-Graduação e Pesquisa em Letras e Linguística, Campinas, n. 18, p. 127-141, 2005. 